68 | PRACTICAL NEUROLOGY
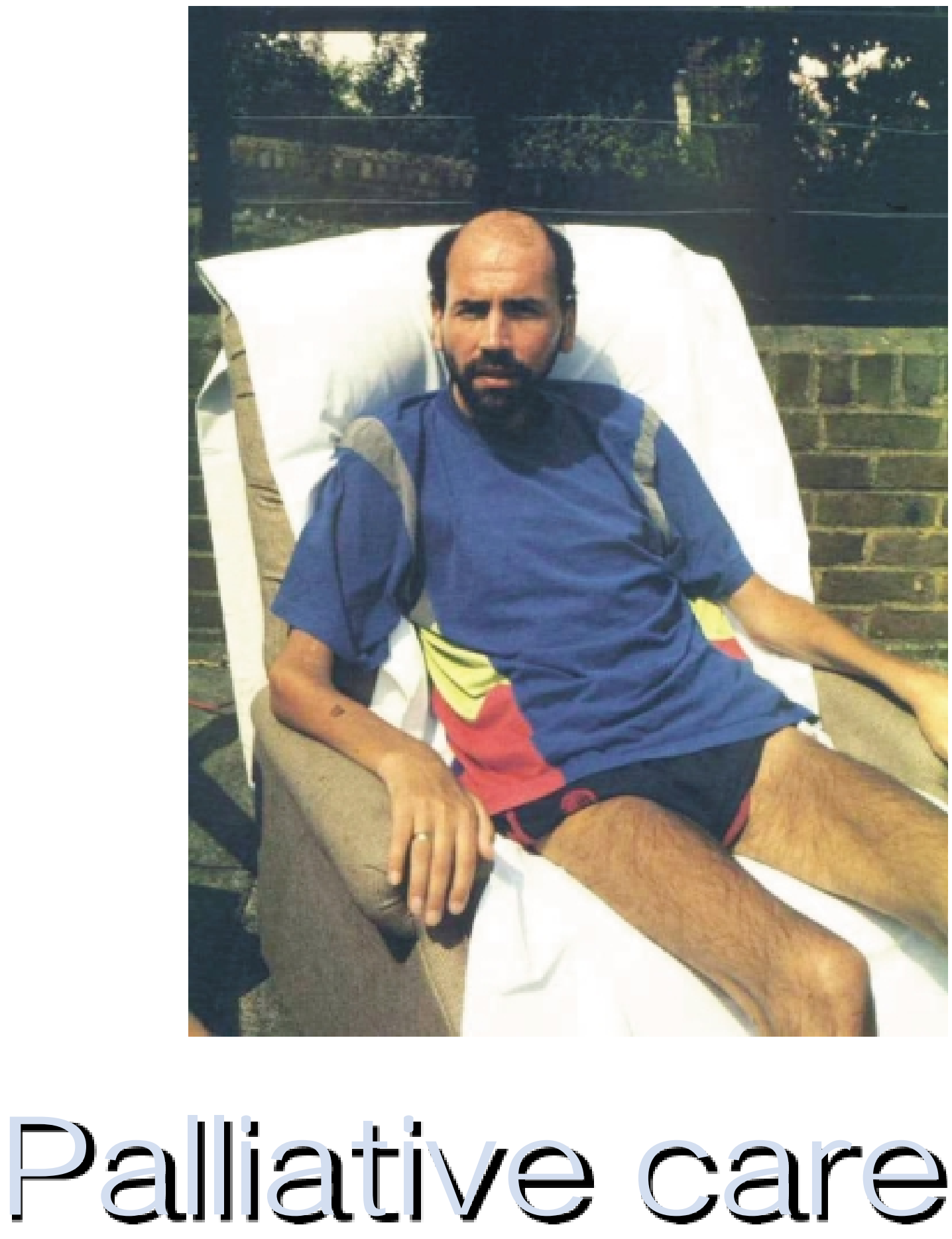

for motor neurone disease 


\section{David Oliver}

Wisdom Hospice, St Williams Way, Rochester, Kent ME12NU, UK; E-mail: dr davidoliver@rochester51.freeserve.co.uk Practical Neurology 2002, 2, 68-79

The palliativecare of a patient with motor neurone disease (M ND) starts even at the time of diagnosis, and this care throughout the disease process is crucial to management in the later stages.

Palliative care is defined as:

'Theactivetotal careof patientswhosedisease is not responsive to curative treatment. Control of pain, of other symptoms, and of psychological, social and spiritual problemsis paramount. The goal of palliative care is achievement of the best possiblequal ity of lifefor patients and their families.' (World Health Organization 1990).

As there is, at present, no cure for M ND, and Riluzole, at best, only slows the progression of the disease. Therefore, the care of patients with M ND is palliativeand this approach will enable them, together with their families, to retain as good a quality of life as possible.

During the disease progression, there are times when there are particular care needs of the patient with M ND:

- at diagnosis, when the patient and family are faced with adiagnosisthat they may havelittle knowledge of and which may be very frightening;

- when a crisis in care occurs, such as the need to consider a new intervention, for example the use of a wheelchair, percutaneous endoscopic gastrostomy, ventilatory support;

- the terminal phase, when there is increasing deterioration and end of life issues are faced. Often these phases are not easily defined. Indeed, different aspects of the progression of the disease may be faced at different times for different patients. All patients with M ND are different, in thedisease progression itself and how they, with their family and carers, copewith the many changes that they face. The challenge of palliative care of these patients is to ensure that all the various aspects of care are considered and actively managed, involvingthepatient and family in any decisionsand changes. Theaspects of care that need to be considered are:
- physical - symptom control, in particular;

- psychological - the effects on the patient;

- social - the effects on the family and carers;

- spiritual - concernsabout themeaning of life and the challenges of the disease.

\section{PHYSICAL ASPECTS OF CARE}

Therearemany different symptomsthat should be considered, some are directly related to the disease process, others to the effects of muscle weakness.

\section{Dyspnoea}

Weakness of the intercostal muscles and diaphragm can lead to increasing respiratory problems - in particular dyspnoea and respiratory failure. The patient may complain of the symptoms of respiratory failure, including morning headache, poor and disturbed sleep, dreaming, orthopnoea, mood disturbance and loss of appetite or of dyspnoea, sometimes on sitting up or when in a swimming pool (Lyall et al. 2000). These symptoms may be very subtle and careful assessment is essential, as patients may not realize they are developing respiratory problems. Dyspnoea is very common and up to $85 \%$ of patients develop the symptom during the disease progression (Oliver 1996).

A fuller assessment of respiratoryfunction may be appropriate, including serial measurement of forced vital capacity, and tests of respiratory function, such as sniff analysis, blood gas estimation and overnight oximetry (Lyall et al. 2000).

Simple measures may be effective initially, such as ensuring the correct position with a slight incline backward in the wheelchair (O'Gorman \& Oliver 1998) (Fig. 1.). The involvement of the wider multidisciplinary team is helpful, particularly the physiotherapist and occupational therapist (O'Gorman \& Oliver 1998; Kingsnorth 2000). Opioid medication can bevery effectiveif other methods of respiratory support are not appropriate or acceptable to the patient (Oliver 1998; Sykes 2000).
The palliative

care of a patient

with motor

neurone disease

starts even

at the time of

diagnosis 


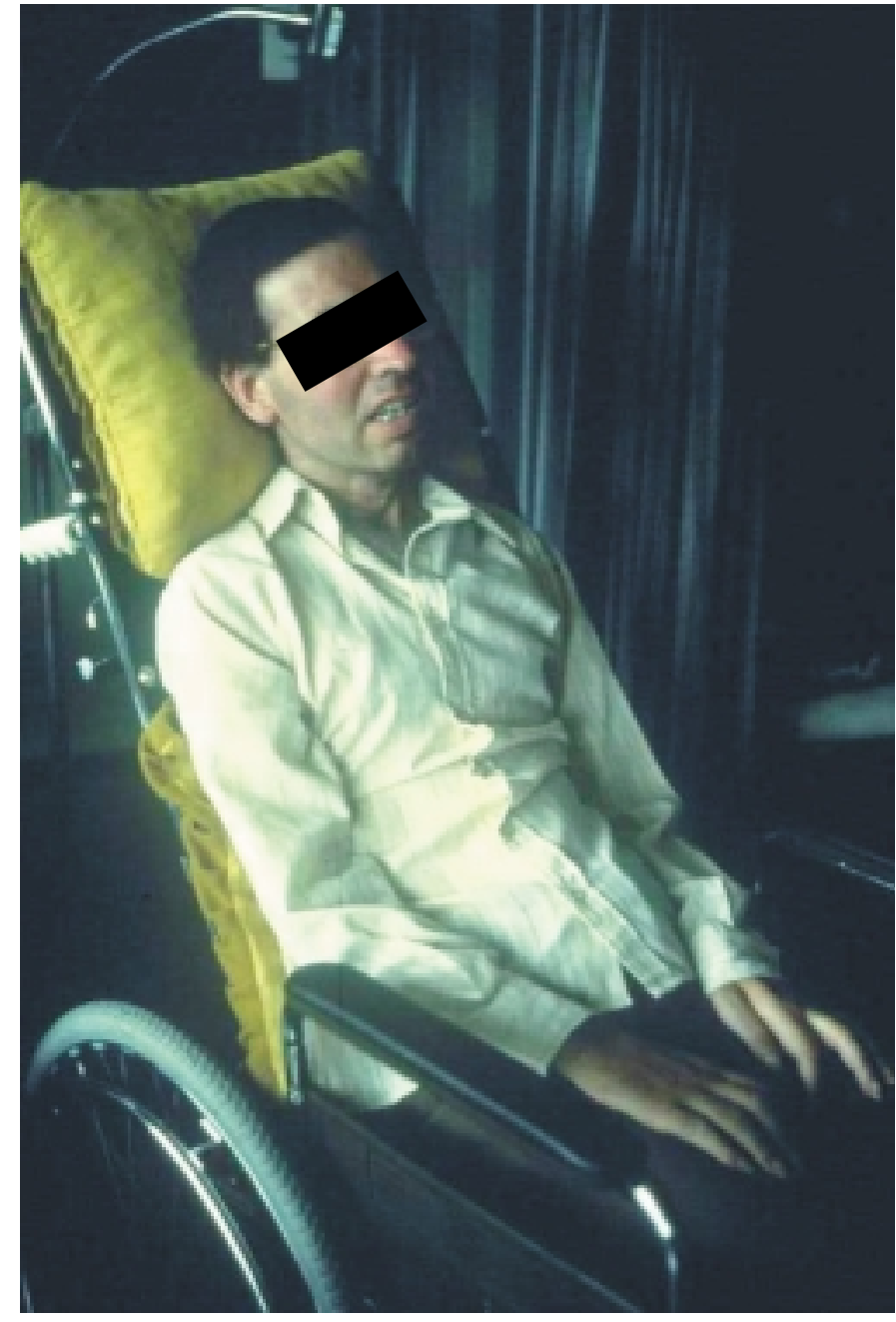

Figure 1 A reclining wheelchair improves the comfort for the patient. Drooling was reduced and he no longer needed to hold a handkerchief to his mouth.
Consideration should begiven to respiratory support, usually non-invasive positive pressure ventilation (NIPPV). NIPPV at nightcan bevery helpful in reducing the symptoms of respiratory failure and so improving the quality of life. However, there must befull discussion with the patient and family becausethey should beaware of future plans and further management if the symptomsworsen again (Lyall etal. 2000). M any patients find that the use of NIPPV increases with time, until some require $24 \mathrm{~h}$ support. If there is further deterioration, there should bea clear management plan in this terminal phase.

On occasion, further respiratory support with tracheostomy ventilation may be considered. Unfortunately, this decision is often taken when there is a sudden deterioration, perhaps before the attending doctors realise that the patient has M ND (Gelinas et al. 2000). There are risks that ventilation may put an increasing burden on the patients, and particularly their families (Gelinas et al. 1998), as they become increasingly disabled and need total care. Approximately $10 \%$ of patients become'locked in', with no method of communication, but with the basic support of life continuing (Gelinas et al. 2000). Patients need to know about the risks of this development when NIPPV is discussed, so that they may take a clear and autonomous decision (Gelinas 2000). The use of ventilatory support opens up many areas of ethical debate and dilemmas, and all involved in the patient's care should be aware of the potential risks and the need to discuss these honestly.

\section{Dysphagia}

The development of dysphagia is a distressing and common symptom, affecting up to $87 \%$ of patients suffering from the disease (Oliver 1996). A careful assessment is essential, and involves a speech and language therapist early in the disease progression (Wagner-Sonntag et al. 2000; Scott \& Foulsum 2000). Careful feeding and theuse of pureed food, to a consistency that easesswallowing for theindividual patient, is helpful (Wagner-Sonntag et al. 2000; Scott \& Foulsum 2000). The placement of a percutaneous endoscopic gastrostomy (PEG) tube can be very helpful in improving quality of life (Gazis et al. 1996) and there is evidence that it may increase survival (M azzini et al. 1995). (Fig. 2.)

The placement of a PEG tube should be discussed early in the development of swallowing difficulties. The PEG tube must be inserted while respiratory function is relatively good forced vital capacity of at least $50 \%$ of expected - to minimisemorbidityand mortalityfrom the procedure (Miller et al. 1999). Careful discussion with the patient and family is important so that they are aware of the potential benefits of PEG, and thePEG tubemay not even beused for any feeding initially. H owever, asswallowing deteriorates, the PEG can be used increasingly, in conjunction with a decreasing oral intake (Wagner-Sonntag et al. 2000).

As a result of reduced swallowing, many patients develop drooling: $23 \%$ in one study (Oliver 1996). This can be very distressing for both patient and family, especially as on many occasions the patient may be treated by others as if they are of low intelligence. Anticholinergic medication can be effective in reducing saliva and drooling: atropine 300-600 g tds; sublingual hyoscine $300 \mathrm{~g}$ tds; hyoscine hydrobromide transdermal patch $1 \mathrm{mg} / 72 \mathrm{~h}$ (Scopoderm TTS), although this may cause 


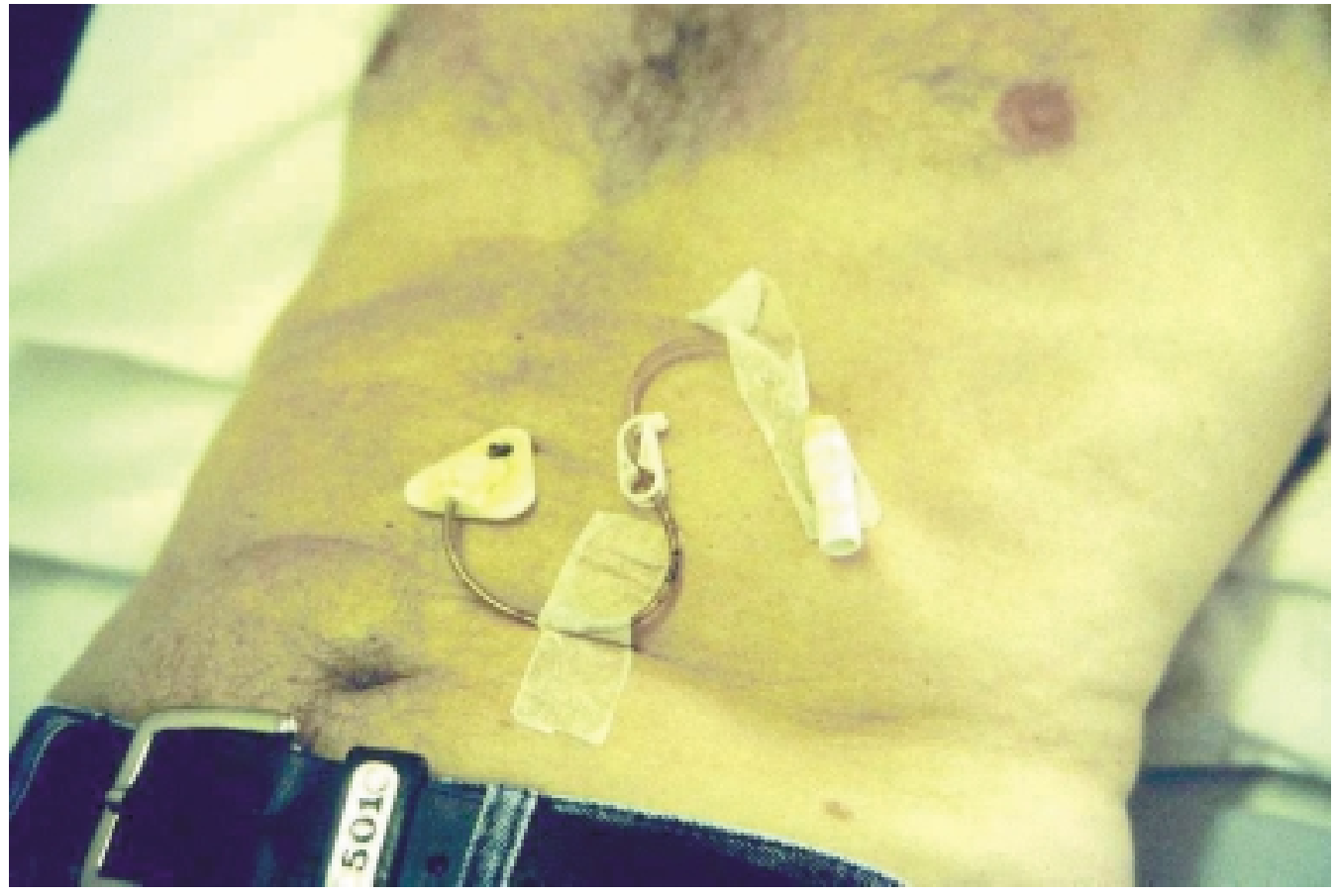

skin irritation. Tricyclic antidepressants - amitriptylinestarting at $25 \mathrm{mg}$ at night and slowly increasing - can also be helpful (Scott et al. 2000). Injection of Botulinum A Toxin into the salivary glands has been suggested (Geiss et al. 2000) although further research is required. On occasions, a continuous subcutaneousinfusion by syringe driver of an anticholinergic drug may be required: glycopyrronium bromide $600 \mathrm{~g}-1.2 \mathrm{mg} / 24 \mathrm{~h}$; or hyoscine hydrobromide 600 g-2.4 mg/24 h (Oliver 1996; Sykes et al. 2000). Radiotherapy to thesalivary glands has been suggested but can leave a very dry mouth, or the production of thick secretions.

Somepatientshavegreat problemswith thick tenacious secretions, which may be difficult to clear with poor respiratory muscle function. Thereisevidencethat betaadrenergic receptors are involved in the production of these thicker secretionsand propranolol - at an initial doseof $10 \mathrm{mg}$ tds - has been found to be useful in limited trials (Sykes 2000; Scott \& Foulsum 2000).

\section{E motio nal la bility}

Emotional lability (pseudobulbar affect) is common in MND patients, particularly those with bulbar disease, and one study showed a prevalence of $23 \%$ (Oliver 1996). There is increasing evidence that this symptom is related to frontal lobe damage and dysfunction. It can be particularly distressing to both patients and families because the patient may feel as if their emotions are out of control and that they are going mad (Borasio \& Voltz 1997). If there is a suspicion of emotional lability, especially in patients with bulbar disease, it is often helpful to explain that thesymptom may occur. Patients may berelieved that thesymptom isunderstood and that they can discuss their fears and concerns (Borasio \& Oliver 2000). Theexplanation that thesymptom is aknown part of the disease and is understood may be the most helpful intervention in reducing anxiety.

Treatment with antidepressants, such as amitriptyline starting at $25 \mathrm{mg}$ at night, can be helpful. Anxiolytics, such as benzodiazepines may also behelpful (Borasio \& Oliver 2000).

\section{Weakness}

Progressiveweaknessisinevitableasthedisease progresses. There are no proven treatment regimes, and although creatine has been suggested to be of help, studies haveyet to confirm this. Explanation is essential in allowing the patient and family to copewith theincreasing weakness so they feel able to accept help, in the form of aidssuch as astick, wheelchair or electricraising chair. Physiotherapy is very helpful in allowing thepatient to makethe most of their remaining power, and in adjusting to increasing disability (O'Gorman 2000).

\section{Pain}

Although there is little evidence of sensory
Figure 2 The insertion of a PEG can improve the quality of life. This patient was able to visit his brother in Australia after the procedure, without the anxiety of whether he would be able to eat. 
nerve involvement, pain is a common symptom, with studies showing a prevalence of up to $73 \%$ (Oliver 1996). The pain may bedueto:

- musclestiffnessand spasm in spasticity, so the use of muscle relaxants such as baclofen can behel pful (Borasio \& Oliver 2000);

- joint pains due to the altered muscle activity around the joint - the physiotherapist can help in the assessment and management of this type of pain by ensuring good positioning and encouraging passive movements (O'Gorman 2000);

- skin pressure pain due to immobility

The treatment of skin pressure pain is initially with a simple analgesic, such as paracetamol or codydramol, on a regular basis. H owever, many patients benefit from the use of opioid analagesics. Regular morphine, as morphine elixir, starting at $5 \mathrm{mg}$ every $4 \mathrm{~h}$, or modified release tablets or capsules (MST or Zomorph) starting at $10 \mathrm{mg}$ every $12 \mathrm{~h}$, can be very effective (Oliver 1998). Studies have shown that morphine can beused safely if it is titrated carefully to the patient's pain and the median dose in onestudy was $60 \mathrm{mg} / 24 \mathrm{~h}$ and the mean duration of use was 95 days (Oliver 1998). Q uality of life can be greatly improved, without necessarily shortening life, with the correct use of morphine. If swallowing is affected, a transdermal preparation, such as fentanyl transdermal patch, starting at $25 \mathrm{~g} / \mathrm{h}$, or a continuous subcutaneous infusion by syringedriver may be used at a dose of morphineor diamorphine equivalent to that given orally, or starting with (dia)morphine $15 \mathrm{mg} / 24 \mathrm{~h}$ (Sykes 2000). Diamorphine has no particular advantageover morphine, other than it is more soluble, and morphine can be used as effectively.

\section{Insomnia}

From early in the disease, patients may find sleep difficult. A careful assessment is essential as there may be several causes:

- anxiety about the diagnosis, or disease progression;

- depression as a result of the disease process;

- fear of not being heard by carers when there is reduced speech, particularly if extra help is required in moving in bed;

- musclecramps or spasticity;

- dysphagia and problems with clearing secre tions, or fear of drooling;

- respiratory insufficiency, with nightmares, dreams and dyspnoea.
Causative factors must be sorted out before treatment is started. There may only need to be some simple action, such as the provision of a sensitive buzzer to allow a patient with reduced speech to call for help, or appropriatemedication may be needed, such as antidepressants, muscle relaxants, anticholinergics or anxilolytics.

\section{Cough}

Cough may develop:

- as the respiratory muscles weaken and it becomes increasingly difficult to clear secretions from the chest - the reduction of these secretions, particularly at night, may be helpful, in conjunction with physiotherapy;

- as swallowing efficiency declines and saliva trickles down into the airways, stimulating the cough reflex;

- if there is a respiratory tract infection, upper or lower, with increased secretions and a reduced ability to clear them.

Treatment should be of the underlying cause (Lyall et al. 2000). Opioids may be helpful if cough remains troublesome (Oliver 1998).

\section{Constipation}

Constipation may occur in patients taking a reduced diet, or with reduced physical activity, particularly when medication has been prescribed that can lead to constipation, such as opioids or anticholinergics - one study reported $53 \%$ of patients complained of constipation (Oliver 1996). Prevention of constipation is important, by ensuring adequatehydration, a balanced diet and aperients (Borasio \& Oliver 2000).

\section{PSYCHOLOGICAL ASPECTS OF CARE}

From the time of diagnosis, and often before thediagnosis has been made, patients may have concerns and fears - of the diagnosis, the treatment, the disease progression, dying and death (Borasio et al. 2000). All those involved in the care of people with MND should be aware of these possibleconcerns and fearsand bewilling to explorethese issues if and when necessary.

\section{Fears of the diagnosis}

$M$ any patientsand their families havelittleprior knowledge of M ND and fear theunknown. Unfortunately, many books emphasise the distress of the disease and death from M ND. M oreover, the press coverage of people with MND has tended to stress the problems of the disease, 
especially when covering the people with MND who have been in the courts pressing for the right to die. These issues may need to bediscussed and thealternative views presented.

\section{Fears of dependency and dis ability}

$M$ any patients fear loss of control and the loss of independence as the disease progresses. Ways of coping with changes may need to beexplored and psychosocial support, together with practical support, such as the provision of a wheelchair, may be necessary (Kingsnorth 2000; O'Gorman 2000).

\section{Fears of dying}

These are common, especially fears of dying from choking or suffocating. Thereisnow evidencethat, with good palliativecare, death is not distressing and most often it is peaceful (Neudert et al. 2001).

\section{SOCIAL ASPECTS OF CARE}

M ost patients are part of a wider group of family or carers. They too will beaffected by theprogression of thediseaseand may have similar concerns.

\section{Fears of the diagnosis}

Similar to the fears of the patient, but there may be differences and it may be necessary to enable them to discuss their fears together. The support of a social worker or psychologist may be helpful (Borasio et al. 2000; Gallagher \& M onroe 2000).

\section{Communic ation issues}

These may occur within the family group, particularly when the diagnosis or prognosis are not shared within the family.

\section{Financial problems}

Thesemay occur when thepatient and then their spouseor carer have to leave paid employment due to increasing disability or care needs. This can lead to stresses within relationships and increasing financial pressures. A social worker can be helpful in ensuring thenecessary support is available(Gallagher \& M onroe 2000).

\section{Sexuality}

This may becomean issue for many patients, although they may find this difficult to admit. The sexual practices of a couple may haveto changeas disability increases and they may need encouragement and help to discuss the issues together, and to consider alternatives. Theneed to express love is important to many couples and theseissues, if not addressed, may lead to distress, which is often not acknowledged.

\section{Fear of dying}

Families and carers may have their own fears about the process of dying: everyone has their own experiences and fears about death. They may need to beencouraged to expresstheseconcerns openly so they can feel moreable to carefor thepatient and cope

\section{Quality of life}

can be greatly improved, without necessarily shortening life, with the correct use of morphine 
with both their own and the patient's concerns (Gallagher \& M onroe 2000).

SPIRITUAL ASPECTS OF CARE

As someone faces increasing disability and the possibility of an early death, they may start to consider the deeper meaning of life and death. This expression may not necessarily be in the form of organised religion, but in terms of 'natural religion', with concerns over thefuture. Time may be needed to talk about these issues and it is easier to do so while speech is reasonably intact, as to discuss these deep issues by means of an electronic communication aid can bevery difficult.

\section{ULTID IS C IPLINARY CARE}

To enable a full assessment of the problems and concerns of a patient with M ND, and their family, it isessential that a multidisciplinaryapproach is used. Theteam includes:

- neurologist/physician;

- nurse;

- chaplain/religiousleader;
- dietician;

- occupational therapist;

- physiotherapist;

- social worker/counsellor;

- speech and language therapist.

All these people may need to be involved in the careand support of thepatient with M ND and it isessential that thereis a co-ordinated approach to thecareprovided. Thismay also involveother professionals and support workers, including:

- social services caremanager, or link worker

- disability services;

- specialist nurses in neurology clinics;

- research workersin MND;

- Motor Neurone Disease Association: the Regional CareAdvisors who are able to provide support and information for patients, families and professionals;

- the local MND Association Branch, with local volunteer visitors for support and the opportunity to meet and discuss M ND care (Fig. 3);

- primary health care team of general prac-

Figure 3 Consideration of patient autonomy is important. This man in South Africa was able to remain at home with the support of his wife and family, and the assistance of the MND Association.

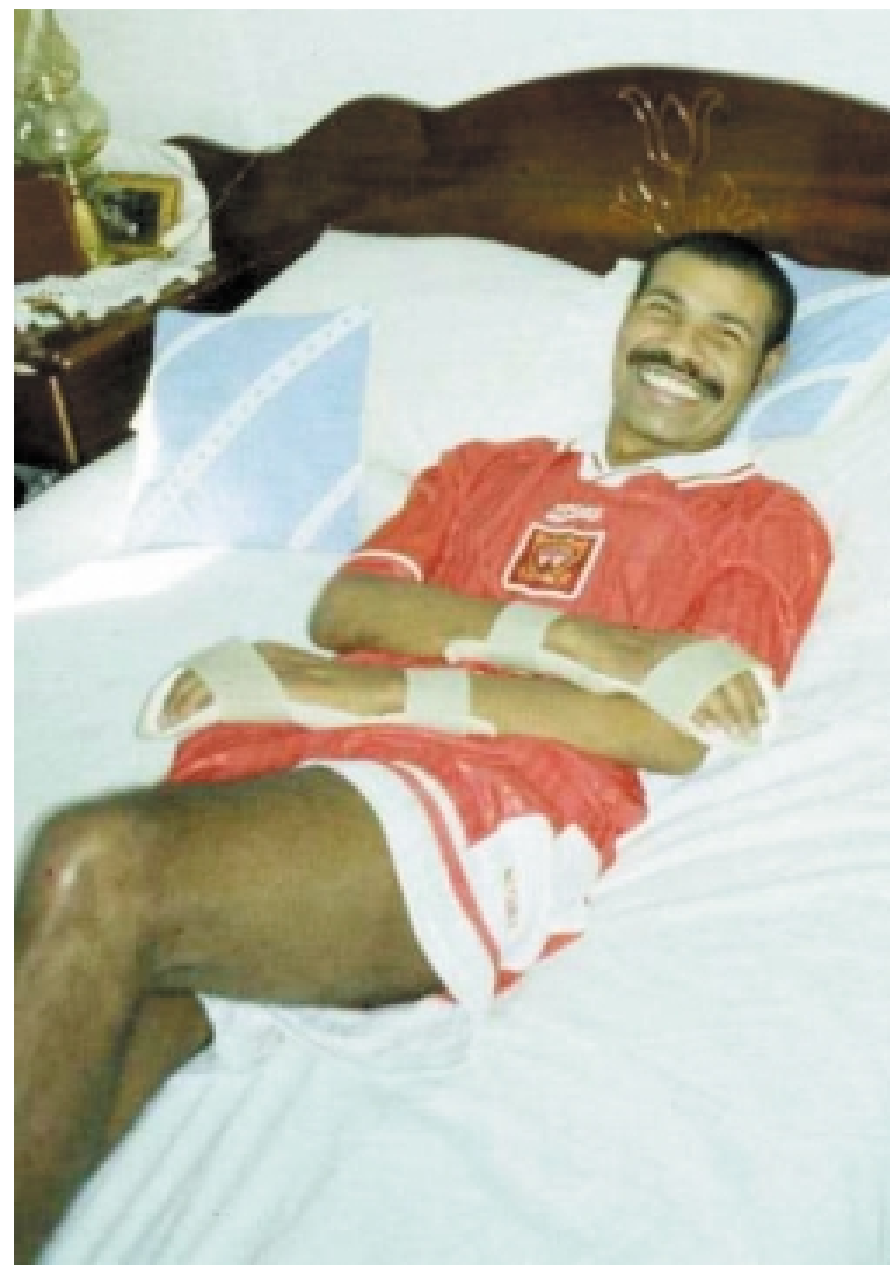




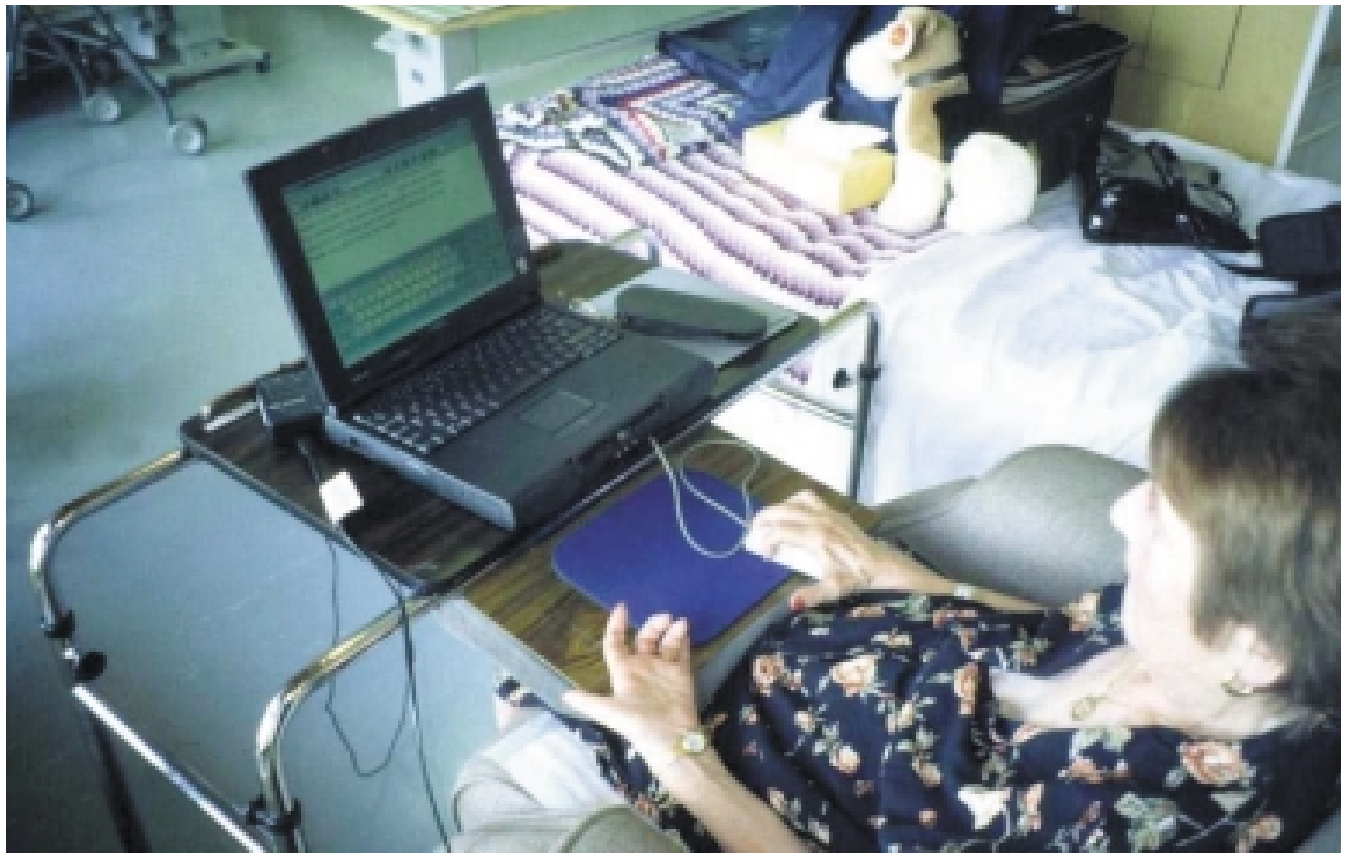

titioner and community nurse who will be providing on going care at home.

With so many different people involved there is a real possibility of overlapping care, or missing areas of care. Moreover, the patient and family can feel overwhelmed, and confused as to what is being provided. Their own homemay feel invaded by all the visiting professionals (Pegg 1994).

To facilitate multidisciplinary care, a coordinated approach is required. In many areas there are developing M ND teams, meeting to discuss patient care, ensure a multidisciplinary approach and help in the education of other professionals (Holmes 2000). These may develop from different backgrounds, depending on the local expertise, including:

- neurology services and the MND care and research centres (Holmes 2000);

- rehabilitation services (M olloy 2000);

- palliative care services (Oliver 1996; Oliver 2000);

- the M N D Association (Holmes 2000). Theaims of these teams are to:

- ensure a multidisciplinary assessment;

- co-ordinatethe visits of professionals;

- provide a link for patients and families with theteam, often via a link worker;

- co-ordinate the inter-agency working that is necessary;

- provideappropriate, and timely, information for patients and families, with sensitivity and respect;
- anticipate the emotional and physical needs of patients;

- offer support to patients and families, and to provide the information for autonomous decision making;

- ensure continuity of careall through the disease progression (Holmes 2000).

Throughouttheteam approach, it isessential that theteam aimsto facilitateand enablepatientsand families, focuseson their needsand concerns, and involves all the family in the care and decision making, with the patient's agreement.

The needs of patients and families will vary greatly according to the disease progression, the family's own resources and previous coping mechanisms, and the availability of resources and support. However, there may be specific needs as the disease progresses. At the time of diagnosis, theremay bea particular requirement to provideinformation, and support patient and family with their concernsand fears. Thewaythis information is imparted and the support provided at this time can affect the later care of the patient and family. Later reactions to problems can beprofoundly altered by thecareat thistime. A supportiveand empathetic approach, with the opportunity for questions and a sympathetic reaction by the professional, is very important in showing that support will be available later so that thepatient and family know they can discuss issues openly with the caring team (Borasio et al. 2000; Gallagher and M onroe2000). (Fig. 4.)
Figure 4 Laptop computers and other communication aids can help communication and enable independence. This lady was able to continue communication with her family and carers, using the voice system. 
As the disease progresses there may be specific times when members of the team should be involved, as problems evolve. As mobility decreases the physiotherapist and occupational therapist may be of most help. If speech and swallowing deteriorate, the speech and language therapist and dietician should be involved, and asearly aspossibleso a relationship can bedeveloped. With all thesechanges, theremay beincreasing needsfor support and for a social worker, counsellor or clinical psychologist to be available to allow patients to talk about their fears and reactions (Kerkvliet 2000). Patientsmust bepsychologically ableto discuss new treatment plans or interventions, for if they are unable to discuss the issues the intervention may be rejected and the care offered compromised. For instance, the discussion about theinsertion of a PEG tube may have to be undertaken over a period of time, allowing the patient to understand the problems and to face the issues involved. With the appropriate and sensitive provision of information, an autonomous decision can betaken more easily.

a crisis it is

often helpful to

discuss the use

of medication,

and to provide

the medication

for the patient's

house

\section{THE TERMINAL STAGES}

As thepatient deteriorates, thereisan increasing need to assess and look at all theconcernsand problems of thecarersand family as much as those of the patient. The control of symptoms is essential and thewider multidisciplinary team should be involved, in a co-ordinated way. The deterioration of a patient with M ND is variable. Patients usually deteriorate slowly and it gradually becomesapparent that thediseasehas reached theterminal stage, but for many patientsthechangesarerapid, over afew days ( Neudert et al. 2001). One study showed that for $65 \%$ of patients the period between theacutedeterioration and death wasunder $24 \mathrm{~h}$ (Neudert et al. 2001).

The cause of death is usually respiratory failure, if invasive ventilation is not considered to be appropriate. The patient develops a respiratory tract infection, which initially may seem trivial, but the respiratory function deteriorates and over a few days, sometimes over a few hours, there is a rapid deterioration leading to death (Neudert et al. 2001). One study showed that $86 \%$ died from respiratory failure, $6 \%$ from heart failure, $4 \%$ from pneumonia, $1 \%$ from suicide and $3 \%$ from other causes (Neudert et al. 2001).

Patients and their families fear the deterioration, and in particular choking or suffocating (Oliver 2000; O'Brien et al. 1992). H owever, distress is rare and with good palliative care, including the management of dyspnoea, pain and swallowing problems, and support of patient and family, the vast majority of deaths from M ND can be peaceful (Neudert et al. 2001; O'Brien et al. 1992). An international study showed that only $5 \%$ of a group of 171 patients in the UK and Germany died in distress, and 91\% died peacefully (N eudert et al. 2001).

\section{Co-ordinated care}

The care in the later stages of M ND will involve carefully coordinated care. Anticipating crisesisimportant - ensuringthat all involved in the care are aware of the plansfor care, so that if there 
are increasing respiratory problems the patient, family and carers are all well aware of the patient's wishes so that unwanted and inappropriate intervention, such as ventilation, is avoided. Theprovision of medication for a crisis, together with discussion within the family, can be very hel pful in allaying theconcernsabout a crisisfor both patient and family. Themedication isreadily availableif thecrisis, such as breathlessnessor pain, occurs out of hoursand all areprepared for the actions to be taken in such an event (Oliver 1996; Sykes 2000) - seebel ow. Symptom control is maximised, by reassessment on a regular basis and close involvement of the multidisciplinary team. Pain, dyspnoea and drooling should be addressed in particular. Opioids may be very hel pful, as outlined above. As the patient deteriorates, oral medication may be difficult and alternatives haveto beconsidered, such as a continuoussubcutaneousinfusion by syringedriver (Sykes 2000). Thiscan allow opioids to begiven, usually as (dia)morphine (starting at a dose appropriate to oral morphine, or at $10-15 \mathrm{mg} /$ $24 \mathrm{~h}$ ), together with midazolam as sedation and to reducestiffness (at a dose of 20-60 mg/24 h) and an anticholinergic to reduce respiratory secretions and respiratory distress (such as glycopyrronium bromide $1.2 \mathrm{mg} / 24 \mathrm{~h}$ or hyoscine hydrobromide $1.2-3.6 \mathrm{mg} / 24 \mathrm{~h}$ ) (Oliver 1996; Oliver 1998; Sykes 2000).
To anticipatea crisis it is often hel pful to discuss the use of medication, and to provide the medication for thepatient's house. The'Breathing Space' programme of theM N D Association has been produced to facilitate this discussion about the dying process and thereareleafletsfor the patient and family and for the general practitioner with points for discussion. The MND Association also provides a box for the storage of medication, together with a leaflet on the suggested medication and its use (Fig. 5). The box has two parts:

- one section for professionals with the suggested medication [(dia)morphine, in a dose appropriate to the oral opioid, or at $5 \mathrm{mg}$ $10 \mathrm{mg}$; midazolam for sedation and muscle relaxant at a dose of 5-10 mg; glycopyrronium bromide 200 micrograms or hyoscine hydrobromide at a dose of 400 micrograms for the reduction of respiratory secretions]; water for injections; syringes and needles;

- one section for families, if appropriate after discussion with the family, containing diazepam enema $10 \mathrm{mg}$ to be given rectally by the family in the crisis situation while they arewaiting for professional assistance (Oliver 1996; Sykes 2000).

Thesupport of patient and family isvery important at this time and regular contact is helpful. The family need to have a point of contact for advice at all times.

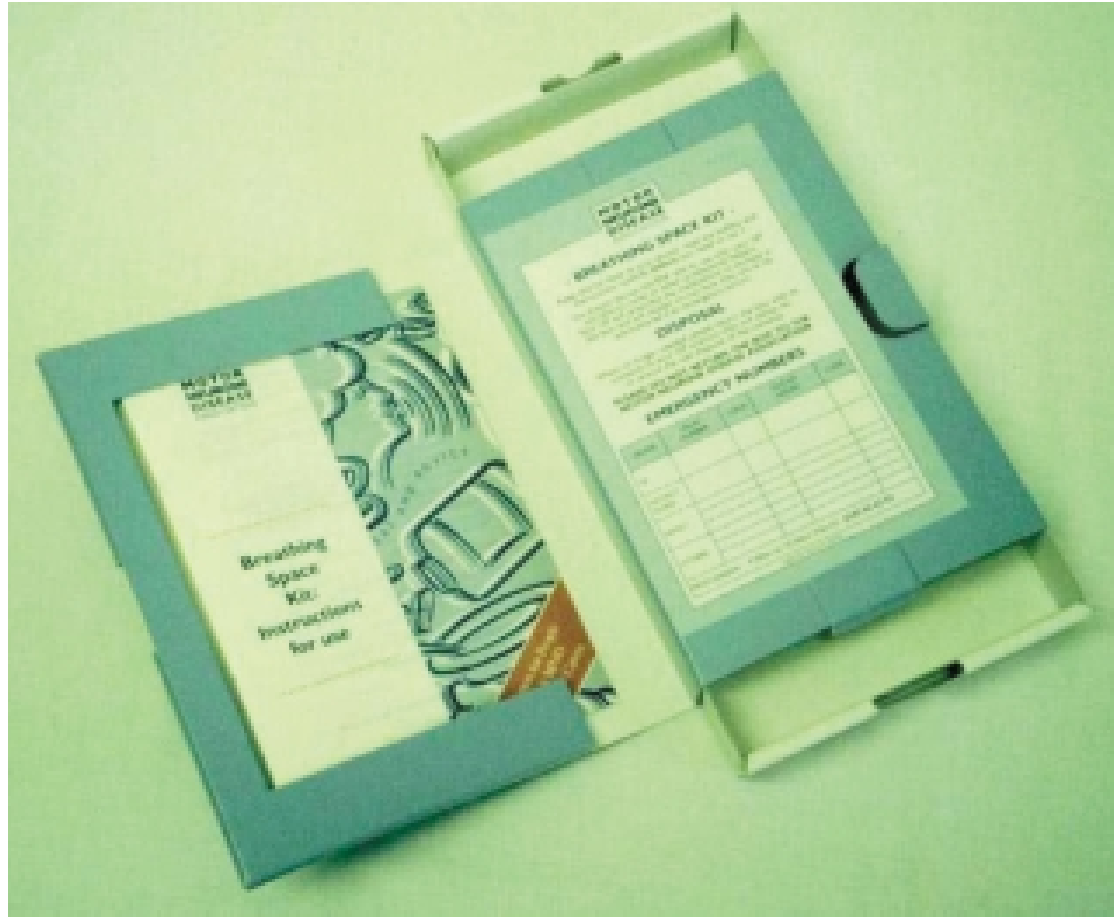

Figure 5 The 'Breathing Space' programme. This allows the discussion of end-of-life issues between the patient and family and carers, and the provision of medication in anticipation of the development of a crisis. 
Theprofessionalsinvolved in thecare of people with MND may also benefit from support, as the patient deteriorates (Kerkvliet 2000). All too often the professional carers are ignored although they may al so be affected by the deterioration and death of a patient who they have known for a long time. The multidisciplinary team can be very supportive if all are aware of theseneeds and a team meeting can hel p in providing this support (Kerkvliet 2000).

Communication among all involved is essential. It is important that all theteam, including the primary health care team, are aware of the change in emphasis in care as the terminal stages of the disease are reached. Some members of the team may have an altered role in these later stages, for example occupational therapy requirements may reduce and the role of the physiotherapist is more focussed more on ensuring comfort than on aiding mobility. It is also important to ensure that the patient and family are aware of this change in care, and are fully involved in making these decisions.

\section{Specialist pallia tive care}

Specialist palliative care can be very helpful throughout the disease progression and over $70 \%$ of hospices and other specialist palliative careprovidersin theUK areinvolved in thecare of people with MND (Oliver \& Webb 2000). Theservices can provide:

- support at home with the multidisciplinary home care (Macmillan) team providing support and advice for patient, family and primary health careteam;

- support in the hospice or palliative care unit: respite care; symptom control and multidisciplinary team assessment; terminal care in the later stages of the disease;

- support for care at home with day hospice care, providing respite for families and the opportunity for assessment and socialization;

- support in hospital with hospital palliative care teams, providing support and advicefor hospital staff;

- psychosocial and bereavement support (Gallagher and Monroe 2000; Oliver \& Webb 2000).

In thepast, theroleof special ist palliativecarehas often been more in thelater stages of the disease (O'Brien et al. 1992). H owever, for theprovision of optimum care, this role is increasingly seen to be important from the time of the diagnosis, or soon after. In this way the specialist palliative care team can work together with other agenciesand build up a relationship with the patient and family. This is particularly important when there are bulbar symptoms, because it is very difficult to help patients communicate their fears and deeper concerns if speech has al ready been lost and communication limited to a communication aid. If theaim of careis to enablethe patient to be fully involved in their care, communication is important and the longer term relationship can facilitate this.

\section{BEREAVEMENT}

The care of the family of someone with M ND may continue after the death of the patient. Bereavement careisimportant, although for many families there have been so many continual losses throughout the disease progression that the death is only one further final loss (Centers 2000). Theremay bemixed emotions, with feelings of relief that the disease has ended, along with feelingsof guilt that with such alossrelief is inappropriate. Counselling and support may be hel pful for many families (Gallagher \& M onroe 2000). Families may also ask for further advice and information about the risks of M ND in the family and timemay beneeded to reassurethem that their family is at no higher risk. In the rare families with familial MND, counselling and genetic testing may benecessary.

\section{CONCLUSIONS}

The development of the Practice Parameters in the USA (M iller et al. 1999) has stimulated all involved in the care of patients with MND to look carefully at the care provided. Although, at present, there is little evidence for many of the interventions and treatments used, there is an increasing evidence base. The use of such guidelines will increase over the coming years (Mitchell 2000) and in the UK there are shortened guidelines for the management of M ND (M ND Advisory Group 1999).

The palliative care of M ND starts at the time of diagnosis. With careful multidisciplinary assessment of the various concerns and problems of the patient and family, it is possibleto reduce the effects of the disease progression, maintain the patient's remaining activities, and enable the patient and family to livelife as fully as possible. We can now tell patients, that with good palliativecare, quality of lifecan bemaintained, and that death will usually bepeaceful. 


\section{USEFUL WEBSITES}

- World Federation of Neurology site, with regularly updated news (www.wfnals.org);

- The International Alliance of ALS/M ND Associations (www.alsmndalliance.org);

- TheUK M otor Neurone Disease Association (www.mndassociation.org);

- TheAmerican ALSAssociation (www.alsa.org);

- The Scottish Motor Neurone Disease Association (www.scotmnd.org.uk);

- TheCananadian ALSAssociation (www.als.ca);

- The Les Turner Foundation in Chicago (www.lesturnerals.org);

- The American Muscular Dystrophy Association, involved in ALScare(www.mdausa.org).

\section{REFERENCES}

Borasio GD \& Voltz R (1997) Palliative care in amyotrophic lateral sclerosis. Journal of Neurology, 244 (Suppl. 4), S11-S17.

Borasio GD \& Oliver D (2000) The control of other symptoms. In: Oliver $D$, Borasio GD Walsh $D$, eds. Palliative Care in Amyotrophic Lateral Sclerosis. Oxford, Oxford U niversity Press, pp. 72-81.

Borasio GD, Sloan R \& Pongratz D (2000) Breaking the news. In: Oliver D, Borasio GD Walsh $D$, eds. Palliative Carein Amyotrophic Lateral Sderosis. Oxford, Oxford University Press, pp. 29-41.

Centers $L$ (2000) One day at a time: the experiences of an ALS caregiver. In: Oliver D, Borasio GD Walsh D, eds. Palliative Care in Amyotrophic Lateral Sclerosis. Oxford, Oxford University Press, pp. 183-7.

Gallagher D \& M onroe B (2000) Psychosocial care. In: Oliver D, Borasio GD Walsh D, eds. PalliativeCarein Amyotrophic Lateral Sclerosis. Oxford, Oxford University Press, pp. 83-103.

Gazis A, Rawlings JR, Allison SP \& Jefferson D (1996) A prospective study of nutritional changes and of gastrostomy feeding in motor neurone disease. Proceedings of the N utrition Society, 55, 146a.

Geiss R, Naumann M, Werner E et al. (2000) Injections of botulinum toxin $A$ into thesalivary glandsimprove sialorrhoea in amyotrophic lateral sclerosis. Journal of Neurology, N eurosurgery and Psychiatry, 69, 121-3.

Gelinas D (2000) Amyotrophic lateral sclerosis and invasive ventilation. In: Oliver D, Borasio GD Walsh $D$, eds. PalliativeCarein Amyotrophic Lateral Sclerosis. Oxford, Oxford U niversity Press, pp. 56-62.

Gelinas DF, O'Connor P \& M iller RG (1998) Quality of life for ventilator-dependent ALS patients and their caregivers. Journal of the Neurological Sciences, 160 (Suppl. 1), S134-S136.

Holmes T. MND Association of England Wales and Northern Ireland. (2000) In: Oliver D, Borasio GD Walsh $D$, eds. Palliative Care in Amyotrophic Lateral Sclerosis. Oxford, Oxford University Press, pp. 143-7.

Kerkvliet J (2000) The role of the clinical psychologist in the ALS Team. In: Oliver D, Borasio GD Walsh D, eds. Palliative Care in Amyotrophic Lateral Sclerosis. Oxford, Oxford U niversity Press, pp. 126-34.
Kingsnorth C (2000) Occupational therapy. In: Oliver $D$, Borasio GD Walsh D, eds. Palliative Carein Amyotrophic Lateral Sderosis. Oxford, Oxford University Press, pp. 111-117.

Lyall R, Moxham J \& Leigh N (2000) Dyspnoea. In: Oliver D, Borasio GD Walsh D, eds. Palliative Care in Amyotrophic Lateral Sclerosis. O xford, O xford U niversity Press, pp. 43-56.

M ND Advisory Group. (1999) Guidelines for the M anagement of M otor NeuroneDisease (M ND). Endorsed by the Council of the. Association of N eurologistsand circulated to members.

M azzini L, Corra T, Zaccala M , M ora G, Del Piano M \& Galante M (1995) Percutaneous endoscopic gastrostomy and enteral nutrition in amyotrophic lateral sclerosis. Journal of N eurology, 242, 695-8.

Miller RG, Rosenberg JA, Gelinas DF, Mitsumoto $H$, N ewman D \& Sufit R (1999) Practiceparameter: The care of the patient with amyotrophic lateral sclerosis (an evidence-based review). Neurology, 52, 1311-23.

M itchell JD (2000) Guidelinesin motor neuronedisease (M ND)/amyotrophic lateral sclerosis- from diagnosis to patient care. Journal of Neurology, 247 (Suppl. 6), $\mathrm{VI} / 7-\mathrm{VI} / 12$.

Molloy I (2000) Rehabilitation. In: Oliver D, Borasio GD Walsh D, eds. Palliative Care in Amyotrophic Lateral Sclerosis. Oxford, Oxford University Press, pp. 135-42.

Neudert C, Oliver D, Wasner M \& Borasio GD (2001) The course of the terminal phase in patients with amyotrophic lateral sclerosis. Journal of Neurology, 248, 612-6.

O'Brien T, Kelly M \& Saunders C (1992) M otor neurone disease: a hospiceperspective. British M edical Journal, 304, 471-3.

O'Gorman B (2000) Physiotherapy. In: Oliver D, Borasio GD Walsh D, eds. Palliative Care in Amyotrophic Lateral Sderosis. Oxford, Oxford University Press, pp. 105- 11 .

O'Gorman B \& Oliver D (1998) Disorders of nerve I: motor neuronedisease. In: Stokes M , ed. N eurological Physiotherapy. London, Mosby.

Oliver D (1996) The quality of care and symptom control - the effects on theterminal phase of M ND/ALS. Journal of the Neurological Sciences, 139 (Suppl.), 134-6.

Oliver D (1998) Opioid medication in thepalliativecare of motor neurone disease. Palliative M edicine, 12, 113-5

Oliver D (2000) Palliativecare. In: Oliver D, Borasio GD, Walsh D, eds. Palliative Care in Amyotrophic Lateral Sclerosis. Oxford, O xford U niversity Press, pp. 23-8.

Oliver D \& Webb S(2000) Theinvolvement of specialist palliative care in the care of people with motor neurone disease. PalliativeM edicine, 14, 427-8.

Pegg R (1994) A carer's perspective. In: Williams AC, ed. M otor Neuron Disease. London, Chapman \& Hall, pp. 203-12.

Scott A \& Foulsom M (2000) Speech and language therapy. In: Oliver D, Borasio GD, Walsh D, eds. Palliative Care in Amyotrophic Lateral Sclerosis. Oxford, Oxford University Press, pp. 117-25.

Sykes N (2000) End of life care in ALS. In: Oliver D, Borasio GD, Walsh D, eds. PalliativeC arein Amyotrophic Lateral Sclerosis. Oxford, Oxford University Press, pp. 159-68

Wagner-SonntagE, Allison S, Oliver D et al. (2000) Dys- 